Original Research Paper

\title{
Estimating the Scouring Depth of Bridge Pier Using Self- Organizing Neural Networks (SOM)
}

\author{
${ }^{1}$ Abolfazl Rafat, ${ }^{2}$ Gholam Abbas Barani and ${ }^{3}$ Amineh Naseri \\ ${ }^{I}$ Department of Civil Engineering, Sirjan Master of Hydraulic Structures, Sirjan Industrail University, Iran \\ ${ }^{2}$ Department of Civil Engineering, Shahid Bahonar University of Kerman, \\ P.O. Box 76169133, Kerman, Iran \\ ${ }^{3}$ Department of Computer Engineering, Sirjan Industrail University, Iran
}

\author{
Article history \\ Received: 06-10-2017 \\ Revised: 17-11-2017 \\ Accepted: 25-11-2017 \\ Corresponding Author: \\ Abolfazl Rafat \\ Department of Civil \\ Engineering, Sirjan Master of \\ Hydraulic Structures, Sirjan \\ Industrail University, Iran \\ Email: rafatabolfazl@gmail.com
}

\begin{abstract}
Scouring is caused as a result of erosion of river bed by water flow and materials carried by water. This research estimates the scouring depth using self-organizing neural network (SOM). The obtained findings were compared with findings of other models. It was found that selforganizing neural network (SOM) has higher correlation coefficient (0.98), compared to other methods. It was also found that root mean square error (RMSE $=0.112)$ is less than other methods. Estimating the depth of scouring using self-organizing neural network (SOM) method indicated that this method gives better findings, in a way that correlation coefficient in implementing the program with dimensional data is higher value compared to state in which program is implemented with non-dimensional data. In addition, Root Mean Square Error (RSME $=0.09$ ) was seen less in the state of dimensional data. In the current research, using the sensitivity analysis showed that when SOM program is implemented with dimensional data, it will be more sensitive to parameter of average diameter of particles.
\end{abstract}

Keywords: Scouring, Self- Organizing Neural Network (SOM), Bridge Pier

\section{Introduction}

Scouring is one of the most important issues in river and coastal engineering. The piers of bridges, oil platforms, water breakers, buried tubes are among the most important structures threatening their scouring. Bridges, as a very important structure in the communicative arteries in one country, has high importance (Rafat, 2014). Destruction of these structures will be followed by several economic and social consequences. The problems caused by scouring at the pier of bridges, especially during floods, have always been considered as a challenge. Thus, protecting this structure against scouring has high importance. The phenomenon of scouring in the bridges has a negative impact on the structure and the structure of bridge will be threatened, if required actions are not taken to prevent this phenomenon (Ismaeeli, 2007). Scouring refers to erosion in the bed and waterway as a result of passage of flow of water or erosion of the bed of river in downstream of hydraulic structures because of high intensity in the flow of water and thus, vertical flows (Najafzadeh, 2013). In recent decades, much attention has been paid to this phenomenon and many studies have been conducted on it, but the number of these studies does not seem to be sufficient in some areas. As most of the studies on this phenomenon have been conducted at the laboratory scale and they have been based on simplification of the real conditions, shortage of field studies on real samples has been always evident. After general defining of issues related to scouring at the pier of bridges and issues and factors related to it, different relations obtained by different researchers were provided and studies conducted on the real samples were reviewed. In the local scouring of pier of bridges, various factors are involved. These factors are generally classified into three groups, including hydraulic, geometric and geotechnical groups. Hydraulic factors include flow depth parameters in upstream, average velocity of flow in downstream, slope of channel, discharge in the width unit, flow section and the form of waterway, manning roughness coefficient, unit mass of fluid volume, gravity acceleration and kinematic viscosity. Generally, geotechnical factors include parameters related to sediment. Geometric factors also include parameters related to the geometric form of the pier of bridge, including diameter of pier or width of pier perpendicular to water flow, the pier length in direction with flow of water, the pier form, the angle of the axis of bridge with flow direction, distance of piers, the 
smoothness and roughness and the base surface, pier supporting system, floating objects carried by water flow (Najafzadeh, 2013). As various parameters affect this phenomenon and as majority of bridges in world have been destructed as a result of this phenomenon and they have imposed high economic costs, much research has been conducted in recent decades about it. As states in earlier sections, majority of these studies have focused on finding an equation to predict scouring depth as a result of flood. Less attention has been paid to issues related to these, which are involved in the design of bridge structure. Great number of bridges has been built on the group of piers, but a few studies have been conducted on the scouring mechanism in this laboratory state. Some of these studies have been conducted by Breusers et al., 2010). There is less information on the piers of bridges located on sticky materials. In this regard, Najafzadeh et al. $(2013 a ; 2013 b)$ estimated the scouring depth of bridge pier by using GMDH. Until that time, it was limited to simple formulas, which calculated the depth of scouring water depth based on the pier width. In this regard, we can refer to a formula introduced by Neill (1973), used before 2013, while great number of bridges in the world have been located on such materials. The lack of information in such areas on one hand and their applicability in designs have caused that recent domestic and foreign researchers to focus on aspects of scouring around the pier of bridges, which less attention has been paid to them. Coleman conducted studies on the scouring in the group of bridges pier after reaching the bed level to foundation, which piers group has been located on it (2005). Heiydarpour and Kaikhaei (2010) also carried out laboratory studies on the process of changes in scouring depth in the case of binary and ternary piers group. One of the important issues related to the phenomenon of scouring, which the need for wider studies on them is evident; investigating the scouring around the pier of bridges is under the nonpermanent flows. Researchers such as Kothyari et al. (1992) carried out laboratory studies in this regard, while number of these studies is very limited. Additionally, Guven et al. (2009; Azamathulla and Ahmadb, 2012; Azamathulla, 2013; Najafzadeh and Barani, 2011; Najafzadeh and Azamathulla, 2012) carried out studies on estimating the scouring depth numerically. The issue is important since the flow in this state is non-permanent. In the regard, solutions to protect bridges pier based on the weakening of the vortex flow mechanism considering some of the geometric parameters have drawn the attention of some researchers. Using these methods not only increases the safety bridges pier, but also it is useful in reducing the costs related to maintenance of the bridges.Hydrological models have been developed in recent years and they are used in many of the studies. In this regard, models simulating the flow three-dimensionally, they can be very useful due to higher adaptation to the physical nature of the hydrological phenomenon. Numerical simulation of the phenomenon of local scouring using three-dimensional numerical models, which can consider the parameter of time, can be very helpful in better understanding of this phenomenon quantitatively and qualitatively, especially at the scale of time. Additionally, as majority of studies conducted in this regard are experimental studies, investigating the local scouring phenomenon in the pier of bridges will be more useful, given the field conditions and information.

\section{Self-Organizing Maps (SOM)}

Self-organizing maps are a special class of artificial neural networks, used often to analyze complex spaces of data (Brian, 2005). The function of this type of networks is based on converting an input space with desired dimension to a space with les dimension and usually a discrete two-dimensional map. For this reason, these networks are regarded as a tool reducing the dimension. The final goal of using self- organizing maps is achieving the simple model of initial data in order to decrease the computations and complexities in analyzing the data. Self-organizing maps are used widely in various science areas, which the most important of them are data extraction and the analysis of complex spaces (Seo, 2004). Other applications such as networks are clustering, pattern detection (Ana, 2006), analysis of images and sounds (Zampighi, 2004) and error detection, Self-organizingmaps are a special type of Kehonen's network. Kehonen has written many papers and books on self- organizing systems, which self- organizing maps are only part of their wider studies (Kohonen, 2001).

\section{Self- Organizing Maps Topology}

In general, self- organizing maps have a two-layer structure with an input layer and an output layer. The neurons of input layer transmit data to the network. In general, their number is equal to dimension of vectors in the input space. These output layer neurons create the network output according to their specific neighborhood relations defined among them and mutual behaviors on each other (Pei-Chann Chang, 2005). The number of neurons in the output layer depends on the studied issue and defined by user. The input neurons are linked to all output layer neurons by linking weights. Each of these output units, named as reference vectors, are weighed by their coordinates on output page. Then, the weight of neurons indicating their coordinates on output page will be changed based on the learning algorithm, which will be explained in the following sections. The basis of change in neuronal search weights with the highest similarity to the input pattern (winner neuron) and the movement of the mentioned neuron and a group of its neighbors are toward input pattern. The final result of the change in weights is the compressed information and determination of the considered space. 


\section{Learning Algorithm of Self-Organizing Maps}

Self- organizing maps algorithm is a type of algorithm of without observer. Learning algorithm without observer can be determined by first-order equations. These equations describe how network weights are adapted to time or repetition of discrete state. For adapting the weights, a similarity scale or pattern sharing is used to direct the learning process, guiding us to some forms of correlation, clustering, or competitive behaviors of network. The learning algorithm of selforganizing maps is generally based on selecting winner neuron and the movement of the mentioned neuron and some of its neighbors towards the input data. The learning algorithm of self- organizing maps can be summarized in the following steps:

1. Initial step: At this step, a random number is given for the weight of each neuron. Then, an input pattern $X=\left(x_{1}, x_{2}, \ldots, x_{d}\right)$ is applied to the network

2. Determining the winner neon: At this step, the winner neon is determined based on the network similarity criterion. Various similarity criteria can be applied to self- organizing maps, but the most common criterion used in this type of networks is the Euclidean distance. The Euclidean similarity equations are as follows:

$$
\|X-W\|=\left(\sum_{i=1}^{d}\left(X_{i}-w_{i}\right)^{2}\right)^{1 / 2}
$$

Then, the input $X=\left(x_{1}, x_{2}, \ldots, x_{d}\right)$ is compared with all elements available in the network simultaneously. The winner neuron is the neuron with the minimum distance among all reference patterns from input data.

$$
\left\|X-m_{c}\right\|=\min _{i}\left\{\left\|X-m_{r}\right\|\right\}
$$

In which $m_{c}$ is the winner neuron and the $m_{r}$ is the reference vectors.

Determining the neighbor neurons: After identifying the winner neuron, a set of winner neuron neighbors, which their values need to be changed, is determined. Changing the values related to neighbor neurons is generally performed in two forms (Demuth et al., 2004). In the first state, a specified neighborhood radius is selected around the winner cell. In this method, all the neurons of the network that are in specified distance of the winner neuron move with a constant coefficient toward the input. In the second method, all neurons available in the network with unequal coefficients move toward input. This unequal coefficient has the maximum value in the winner neuron and its value decreases as it moves away from the winner neuron.
5-Modificationof the weights: Finally, the weights related to winner neuron and its neighbors should be modified based on the network input. These changes are performed according to the following equation:

$$
m_{r}(t+1)=m_{r}(t)+\alpha(t) \cdot h_{c r}(t)\left[x(t)-m_{r}(t)\right]
$$

In which $x(t)$ is the input vector in time $t, m_{r}(t)$ is the $r^{\text {th }}$ reference pattern in time $t, \alpha(t)$ is the rate of learning in time $t$, and $h_{c r}(t)$ is the neighborhood function defined based on the Kernel function as follows:

$$
h_{c r}(t)=\exp \left(-\frac{\left\|k_{c}-k_{r}\right\|^{2}}{2 \sigma(t)^{2}}\right)
$$

where, $k_{c}, k_{r} \in \mathfrak{R}^{d}$ are the winner neuron and its neighbor reference patterns and $\delta(t)$ is the radius of the kernel function in time $t$, respectively. The result of these cases is modification of the weights and movement of the mentioned neurons to the learning sample. $\alpha(t)$ is the parameter used to control the convergence of the algorithm and it is dependent to repetition. For the stability of the network, it should be $0<\alpha(t)<1$ and it should uniformly decreasing in terms of $t$. learning without supervision in the general state is inevitably more complex than supervisory state, and for this reason, it requires much time for learning the educational patterns Marziazuppa, 2004.

\section{Discussion and Conclusion}

In this study, data derived from a paper entitled "Comparing the GMDH method in two states of education by genetic algorithm and recursive propagation algorithm were used to predict the scouring depth" (Najafzadeh and Barani, 2011). In data collection, 184 groups were identified by Mulias and Abdu, 14 groups were identified by Shepart, 24 groups were identified by Shepart and Millor, 18 groups were identified by Dey and 5 groups were identified by Mia and Nagou. The scouring of bridge pier depends on the factors listed in Formula 5 (Najafzadeh and Barani, 2011):

$d s=f(u, y, d 50, \sigma, D, \mu, \rho, g)$

In Equation (5), it was found that the scouring depth depends on the factors, including flow velocity, the flow depth, average diameter of particles, standard deviation of the particles size, the pier diameter, viscosity, density, and acceleration of gravity.

Then, Buckingham method is used to make parameters non-dimensional. The non-dimensional 
equation of scouring is based on the Equation (6) (Najafzadeh and Barani, 2011):

$$
d s / y=f(F r, D / y, d 50 / y, \operatorname{Re}, \sigma)
$$

$R e$ is a Reynolds number, which its equation is as follows:

$$
\operatorname{Re}=u . D / v
$$

Analyzing the estimate of bridge pier scouring depth using SOM.

As great number of neural networks has been used in predicting the bridge pier scouring depth and SOM neural network has not been used, the current study used this method. It was derived from a thesis written in Ferdowsi University about evaporation, which had five non-dimensional inputs and one output. Findings of dimensional data analysis using the SOM program are as follows:

Based on the Table 1, it is determined that estimating the scoring depth using SOM program in dimensional data has appropriate correlation coefficient, but the RSME error (root mean square error) shows a lower value.

Sensitivity analysis of SOM program in predicting the bridge pier scouring depth for dimensional data.

Based on the Table 2, we conclude that the SOM program is sensitive to parameter of average particle diameter in estimating the bridge pier scouring depth, since correlation coefficient decreased to 0.987 and RMSE error (root mean square error) increased to 0.109 by removing this parameter from the main function and re-implementation of the program. In addition, the Mean Square Error value (MSE) increased in the case of removing the average particle diameter from the program and its implementation.

SOM program analysis in non-dimensional data.

Findings of analyzing the SOM program in nondimensional data are as follows:

Based on the Table 3, it is found that estimating the scouring depth using the SOM program in the nondimensional data has a good correlation coefficient, but the RSME error (root mean square error) also indicates higher value. In this state, the Mean Square Error (MSE) is a good value.

Analyzing the sensitivity of SOM program in predicting the bridge pier scouring depth for nondimensional data.

Table 4 sensitivity analysis of the SOM program for estimating the depth of the bridge scour with nondimensional data.

Based on the Table 4, it can be concluded that the SOM program has been sensitive in estimating bridge pier scouring depth, because it reduced to 0.986 and RMSE error (root mean square error) increased to 0.115 by removing this parameter from the main function and re-implementing of the program.
Table 1: Results of estimating the bridge pier scouring depth using SOM in dimensional data

\begin{tabular}{lll}
\hline Program & RMSE & $\mathrm{R}^{2}$ \\
\hline SOM & 0.091293 & 0.99163 \\
\hline
\end{tabular}

Table 2: Results of sensitivity analysis of SOM program in estimating the bridge pier scouring depth for dimensional data

\begin{tabular}{lrl}
\hline Studied parameter & RMSE & $\mathrm{R}^{2}$ \\
\hline$D_{50}$ & 0.109 & 0.987 \\
$\sigma_{g}$ & 0.092 & 0.991 \\
$\mathrm{D}$ & 0.080 & 0.993 \\
$\mathrm{Y}$ & 30.088 & 0.992 \\
$\mathrm{~V}$ & 0.096 & 0.990 \\
$\mathrm{Fr}$ & 0.078 & 0.993 \\
\hline
\end{tabular}

Table 3: Results of estimating the bridge pier scouring depth using SOM in non-dimensional data

\begin{tabular}{lll}
\hline Statistical parameter & RMSE & $\mathrm{R}^{2}$ \\
\hline SOM & 80.11 & 0.9859 \\
\hline
\end{tabular}

Table 4: Results of sensitivity analysis of the SOM program for estimating the depth of the bridge scour with nondimensional data

\begin{tabular}{lll}
\hline Studied parameter & RMSE & $\mathrm{R}^{2}$ \\
\hline FR & 0.11096 & 0.987 \\
$\mathrm{D} / \mathrm{Y}$ & 0.11566 & 0.986 \\
$\mathrm{~d}_{50} / \mathrm{Y}$ & 0.11107 & 0.987 \\
$\mathrm{Re}$ & 0.11332 & 0.987 \\
$\sigma_{g}$ & 0.10451 & 0.989 \\
\hline
\end{tabular}

Table 5: Comparing the findings of SOM program with findings of other methods

\begin{tabular}{lll}
\hline Method & $\mathrm{R}^{2}$ & $\mathrm{RMSE}$ \\
\hline SOM & 0.9859 & 0.118 \\
GMDH-GP (Najafzadeh & 0.8649 & 0.23 \\
and Barani, 2011) & & \\
GMDH-BP (Najafzadeh & 0.7921 & 0.25 \\
and Barani, 2011) & & \\
Laursen and Toch (1956) & 0.6889 & 0.56 \\
Shen et al. (1969) & 0.7744 & 0.63 \\
Melville and Sutherland (1988) & 0.7056 & 1.46 \\
Johnson (1992) & 0.8464 & 0.42 \\
HEC-18 (Brameier, 2001) & 0.7921 & 0.45 \\
\hline
\end{tabular}

The mean square error (MSE) also increased in the state of removing the mean diameter of particles from the program and its implementing. Comparing the models estimating the bridge pier scouring depth using SOM program.

In this section, findings of various methods were compared with findings of SOM method.

Based on Table 5, it was revealed that the correlation coefficient $\left(\mathrm{R}^{2}\right)$ of the SOM method was greater than that of other methods. Thus, it could be concluded that this method has a higher precision in estimating the bridge pier scouring depth. In addition, the root mean square error (RSME) showed lower error compared to other methods. 


\section{Conclusion}

This paper estimated the bridge pier scouring depth using self-organizing neural networks (SOM) and it was compared with other models used to estimate the scouring depth. It was found in these comparisons that self-organizing approach (SOM) has a higher correlation coefficient compared to other methods. Additionally, the current research also revealed that mentioned method has a lower root mean square error (RSME) compared to other methods used to estimate scouring depth.The correlation coefficient for neural networks (SOM) in non-dimensional data was found to be 0.98 percent in the current research, while it was found to be 0.86 in GMDH-GP method. Moreover, root mean square error (RSME) for the introduced model was found to be 0.11 , while it was found to be 0.23 in other methods, such as GMDH-GP. Neural network with self-organizing approach (SOM) was implemented with dimensional and nondimensional data. It was found that the mentioned network data dimensional data yields better results. The correlation coefficient value in the dimensional state was found to be 0.99 , but it was found to be 0.98 in the same program for non-dimensional data. It was found in this study that selforganizing neural network model implemented with dimensional data is sensitive to parameter of average diameter of particles and this result was obtained in the sensitivity analysis. It was also found that the SOM model implemented with non-dimensional is sensitive to the parameter of pier diameter ratio to flow depth.

\section{Acknowledgement}

Thanks to the distinguished professor Gholam Abbas Barani and Amineh Naseri.

\section{Author's Contributions}

All authors equally contributed in this work.

\section{Ethics}

This article is original and contains unpublished material. The corresponding author confirms that all of the other authors have read and approved the manuscript and there are no ethical issues involved.

\section{References}

Ana, M.F., J.L. Biscaya, J. Aires-de-Sousa and A.M. Lobo, 2006. Geographical classification of crude oils by Kohonen self-organizing maps. Analytica Chimica Acta, 556: 374-382.

DOI: $10.1016 /$ j.aca.2005.09.062
Azamathulla, H.M., 2013. A Review on Application of Soft Computing Methods in Water Resources Engineering. Metaheuristics in Water, Geotechnical and Transport Engineering, pp: 27-41.

Azamathulla, H.M. and Z. Ahmadb, 2012. Geneexpression programming for transverse mixing coefficient. J. Hydrology, 434-435: 142-148. DOI: 10.1016/j.jhydrol.2012.02.018

Brameier, M. and W. Banzhaf, 2001. A comparison of linear genetic program-ming and neural networks in medical data mining. IEEE Trans. Evol. Comput., 5: 17-26.

Breusers, H.N.C., G. Nicollet and H.W. Shen, 2010. Local scour around cylindrical piers. J. Hydraul. Res., 15: 211-252.

DOI: $10.1080 / 00221687709499645$

Brian, S.P., 2005. Using self-organizing maps to visualize high-dimensional data. Computers Geosci., 31: 531-544. DOI: $10.1016 /$ j.cageo.2004.10.009

Demuth, H., M. Beale and M. Hagan, 2004. Neural Network ToolboxTM User Guide. The Math Works, Inc.

Guven, A., H.M. Azamathulla and N.A. Zakaria, 2009. Linear genetic programming for prediction of circular pile scour. Ocean Engineering, 36: 985-991. DOI: 10.1016/j.oceaneng.2009.05.010

Heiydarpour, M. and Kaikhaei, 2010. Examining the process of changes in depth of scouring in pier groups. Proceedings of 7 th International Civil Engineering Congress, (CEC'10), Iran Inc, Natick.

Ismaeeli, T., 2007. Evaluation of the scouring phenomenon in the bridges pier. Master Seminar, Faculty of Higher Education Studies, Islamic Azad University, Tehran South Branch, Iran.

Johnson, P.A., 1992. Reliability-based pier scour engineering. J. Hydraul. Eng., 118: 1344-1357.

Kohonen, T., 2001. Self-Organizing Maps. 1st Edn., Springer Science and Business Media, ISBN-10: 3540679219, pp: 501.

Kothyari, U.C., R.J. Garde and K.G. Ranga Rau, 1992. Temporal variation of scour around circular bridge piers. J. Hydr. Engg. A.S.C.E., 118: 1091-1104.

Laursen, E.M. and A. Toch, 1956. Scour around bridge piers and abutments. Iowa Institute of Hydraulic Research. State University of Iowa.

Melville, B.W. and A.J. Sutherland, 1988. Design method for local scour at bridge piers. J. Hydraul. Eng., 114: 1210-1226.

Najafzadeh, M. and G.A. Barani, 2011. Comparison of group method of data handling based genetic programming and back propagation systems to predict scour depth around bridge piers. Sci. Iran, 18: 1207-1213. 
Najafzadeh, M. and H.M. Azamathulla, 2012. Group method of data handling to predict scour depth around bridge piers. Neural. Comput. Applic., 23: 2107-2112.

DOI: $10.1007 / \mathrm{s} 00521-012-1160-6$

Najafzadeh, M., G.A. Barani and H.M. Azamathulla, 2013b. GMDH to predict scour depth around a pier in cohesive soils. Applied Ocean Res., 40: 35-41.

Najafzadeh, M., G.A. Barani and H.M.R. Kermani, 2013a. Abutment scour in clear-water and live-bed conditions by GMDH network. Water Sci. Technol., 67: 1121-1128.

DOI: $10.2166 /$ wst.2013.670

Najafzadeh, M., G.A. Barani, M.R. Hessami-Kermani, 2013. Group method of data handling to predict scour depth around vertical piles under regular waves. Scientia Iranica, 20: 406-413.

Neill, C.R., 1973. Guide to bridge hydraulics. Roads and Transportation Association of Canada, University of Toronto Press, Ottawa, Canada, pp: 191.

Pei-Chann, C. and L. Chien-Yuan, 2005. A hybrid system combining self-organizing maps with case-based reasoning in wholesaler's new-release book forecasting. Expert Systems Applications, 29: 183-192. DOI: 10.1016/j.eswa.2005.01.018
Rafat, A.B., 2014. Examining the methods used to estimate scouring depth and comparing them with each other. Proceedings of the 2nd National Conference on Civil Engineering, Architecture, Restoration, Urban Development and Sustainable Environment, (DSE'14), Hamadan, Iran.

Seo, S. and K. Obermayer, 2004. Self-organizing maps and clustering methods for matrix data. Neural Networks. 17: 1211-1229.

DOI: 10.1016/j.neunet.2004.06.012

Shen, H.W., V.R. Schneider and S. Karaki, 1969. Local scoura round bridgepiers. J. Hydraul. Div., 95: 1919-1940.

Zampighi, L.M., C.L. Kavanau, G.A. Zampighi, 2004. The Kohonen self-organizing map: A tool for the clustering and alignment of single particles imaged using random conical tilt. J. Structural Biology, 146: 368-380. 